\title{
Chestnut peels: from a food waste to a valuable and functional ingredient for cereal-based products
}

\author{
M Paciulli*, M Rinaldi, T Ganino, B Chiancone, E Chiavaro \\ University of Parma, Italy
}

\begin{abstract}
In the last decade, research dealing with the use of chestnut has received considerable interest due to chestnut's promising potential to produce high quality and healthy products with high nutritional value. It can be consumed as fresh, boiled, or roasted. Besides, chestnut is also ground into flour which can be used in the production of diverse high quality products such as bread, cookie, cake, breakfast cereals and also pasta. A new perspective may be the use of the chestnut pericarp, now considered a waste and that represents from 6 to $10 \%$ of the fresh fruit weight, in formulations for cereal-based products. The use of this by-product, naturally rich in antioxidants and fibers, may represent a way to enhance the chestnut supply chain, making it more sustainable, as well as giving an improved nutritional contribution to the chestnut products.

In the present research work, feasibility of the addition of chestnuts' pericarp in several cerealbased products was studied, particularly bread, biscuits and pasta. Studied products were prepared both with wheat flour and in a gluten free version. Chestnut peels showed a great water absorption capacity with great effects on dough rheological properties regardless the product. Similarly, chestnut peels deeply influenced the appearance of the enriched products with a darker colour and the presence of brown particulates. Moreover, chestnut peels enhanced also total antioxidant content of all tested products. In general, chestnut peels showed many challenges in gluten-free formulations as it competed with other thickening agents for water and hindered the formation of a network responsible of the final product structure.
\end{abstract}

Finally, considering all the tested products, the optimal chestnut peels addition varied from 3 $\mathrm{g} / 100 \mathrm{~g}$ to $7 \mathrm{~g} / 100 \mathrm{~g}$ of the recipe.

Keywords: Chestnut, Uses of Chestnut, Waste management, Cereals, Recycling.

\section{Introduction}

The chestnuts is a gaggle of eight or 9 species of deciduous trees and shrubs within the Hamamelis Dicot genus, within the Fagaceae \{Hamamelis Dicot family\} Fagaceae. They're native to temperate regions of the hemisphere.

The fruit is in the buff and eaten up raw, however it is somewhat astringent, particularly if the investment isn't removed.

Another methodology of ingestion the fruit involves cooking, that doesn't need peeling. Cooking needs rating the fruit before hand to forestall explosion of the fruit because of growth [1]. Once well-done, its texture is slightly almost like that of a tater, with a fragile, sweet, and nutty flavor. This methodology of preparation is standard in several countries, wherever the scored chestnuts is also well-done mixed with a bit of sugar.

Chestnuts is dried and polished into flour, which might then be wont to prepare breads, cakes, pies, pancakes, pastas, cornmeal mush (known in Corsica as pulenda), or used as stuff for stews, soups, and sauces. Chestnut cake is also ready victimization chestnut flour. In Corsica, the flour is cooked into doughnut-like fritters known as frittelli and created into necci, pattoni, castagnacci, and cialdi. The flour is lightweight beige like that from Castagniccia, or darker in alternative regions. it's a decent answer for long storage of nutritious food. Chestnut bread will rest as long as period [2].

The kooky also can be eaten up candied, boiled, steamed, deepfried, grilled, or cooked in sweet or savory recipes. They will want to stuff vegetables, poultry, fowl, and alternative edibles. They on the market contemporary, dried, ground, or canned (whole or in puree) [3].

Candied chestnuts (whole chestnuts candied in syrup, then iced) are sold-out beneath the French name marrons glacés or Turkish name kestane şekeri ("sugared chestnuts"). They appeared in France within the sixteenth century. Towards the top of the nineteenth century, metropolis went into a recession with the collapse of the textile market, notably silk. Clément Faugier, an applied scientist, was trying to find some way to revitalize the regional economy. In 1882 at Privas, he made-up the technology to form marron glacés on an industrial scale (although an excellent variety of the over twenty necessary steps from harvest to the finished product are still accomplished manually) $[4,5]$. Chestnuts are picked in time of year, and candied from the beginning of the subsequent summer for the following Christmas. Thus, the marron glacés eaten up at Christmas are those picked the year before.

Chestnuts are usually addictive to animal fodder. A primary soak in lime water removes their bitter flavour, then they're ground and 
mixed with the standard provender. It is given to horses and cows within the Orient, and to pigs in European nations, France and alternative places. The leaves aren't as at risk of be insecteaten as those of the oak, and are used for fodder

Chestnut timber is ornamental. Brown in color, it's generally confused with oak wood. The two woods' textures are similar. Once in an exceedingly growing stage, with little wood, a tree contains additional timber of a sturdy quality than an oak of identical dimensions. Young chestnut wood has tried additional sturdy than oak for woodwork that must be part within the ground, like stakes and fences. Most chestnut wood production is completed by thicket systems, cut on a 12-year rotation to supply little timber that doesn't split as badly as massive logs. In southern European nations (particularly in Kent), chestnut has historically been fully grown as coppices, being recut each ten years approximately on rotation for poles used for fuel, fencing (fence posts and chestnut paling), and particularly to support the strings up once hops are fully grown.

Dry, chestnut fuel is best burned in an exceedingly closed logburner, as a result of its tendency to spit once on a fire.

Chestnut wood could be a helpful supply of natural tannic acid and was used for tanning animal skin before the introduction of artificial tannins. On a tenth wetness basis, the bark contains vi.8\% tannic acid and therefore the wood thirteen.4\%. The bark imparts a dark color to the tannic acid, and incorporates a higher sugar content, that will increase the proportion of soluble.

\section{References}

1. M Paciulli, IG Medina-Meza, E Chiavaro, et al. Impact of thermal and high pressure processing on quality parameters of beetroot (Beta vulgaris L.). LWT- Food Sci Technol. 2016;68:98-104.

2. M Paciulli, T Ganino, N Pellegrini, et al. Impact of the industrial freezing process on selected vegetables-Part I Structure, texture and antioxidant capacity. Food Res Int. 2014;74:329-337.

3. M Paciulli, M Rinaldi, M Cirlini, et al. Chestnut flour addition in commercial gluten-free bread: A shelf-life study. LWT. 2016;70:88-95

4. M Rinaldi, M Paciulli, A Caligiani, et al. Sourdough fermentation and chestnut flour in gluten-free bread: A shelflife evaluation. Food Chem. 2017;224:144-152

5. T Mazzeo, M Paciulli, E Chiavaro, et al. Impact of the industrial freezing process on selected vegetables-Part II Colour and bioactive compounds. Food Res Int. 2015;75:8997

6. A Pugliese, M Paciulli, E Chiavaro, et al. Characterization of commercial dried milk and some of its derivatives by differential scanning calorimetry. J Therm Anal Calorim. 2016;123:3.

\author{
*Correspondence To: \\ Maria Paciulli \\ University of Parma \\ Italy \\ E-Mail: maria.paciulli@unipr.it
}

